\title{
Red-leafed species for urban "greening" in the age of global climate change
}

\author{
Ermes Lo Piccolo ${ }^{1}$ Marco Landi ${ }^{1,2}$
}

Received: 22 March 2020 / Accepted: 10 April 2020 / Published online: 23 May 2020

(C) The Author(s) 2020

\begin{abstract}
Urban trees provide vital ecosystem services such as mitigating heat island, improving air quality by removing various air pollutants, capturing rainwater, and acting as topsoil carbon storage. The aesthetic value of urban trees is also another feature that has to be considered in the context of urban greening. Classical criteria for the selection of urban trees have to respond to new challenges imposed to the cities in a near future. Global climate change factors increase the harshness of our cities, and thereby the plant resilience to abiotic stresses has also to be seriously considered for planning the urban greening. Red-leafed species, characterized by the permanent presence of foliar anthocyanins, show a greater tolerance to different environmental cues than green-leafed species commonly used in our cities. In addition, red tree species own a great aesthetic value which has been underestimated in the context of urban areas, especially in the harsh Mediterranean cities. In this study, we emphasize the "privilege of being red" from different point of view, in order to drive the attention to the possibility to increase the use of red-leafed species for urban "greening". Some possible negative aspects related to their use are rebutted and the direction of future researches are proposed.
\end{abstract}

Project funding: No funding from projects.

The online version is available at http://www.springerlink.com.

Corresponding editor: Yu Lei.

Marco Landi

marco.landi@unipi.it

1 Department of Agriculture, Food and Environment, University of Pisa, Via del Borghetto 80, 56124 Pisa, Italy

2 CIRSEC, Centre for Climatic Change Impact, University of Pisa, Via del Borghetto 80, 56124 Pisa, Italy
Keywords Abiotic stress - Anthocyanin - Ecosystem service $\cdot$ Photoprotection $\cdot$ Urban forestry

\section{Trees in urban environment: old and new challenges for urban greening}

Beginning with the second industrial revolution, cities have gradually extended their green urban areas to mitigate the overbuilding, with their relative effects on climate and community (Tyrväinen et al. 2005). Nowadays, the terms "green building", "green urbanism" or "green infrastructure" have become very popular and are usually used as a banner for the new urban planning.

Environmental sustainability, improvement of health and socio-psychological issues are only few aspects related to the green planning (Zuo and Zhao 2014; McDonnell and MacGregor-Fors 2016; Song et al. 2018). Some studies have demonstrated that the improvement of the green component in the urban environment can effectively: reduce the phenomenon of heat island, sequestrate atmospheric carbon dioxide $\left(\mathrm{CO}_{2}\right)$, capture rainwater and, improve the air quality (Berland et al. 2017; Song et al. 2018; Xing and Brimblecombe 2020).

Trees are the most important natural element in the urban environment (Tyrväinen et al. 2005); however, the common utilized term "element" is inadequate and completely detached from the concept of living organisms, leading to the idea that urban plants are mere ornamental elements that produce benefits, without thinking about the well-being of plants themselves. This erroneous idea very often leads to planning errors related to the incorrect choice of plants in urban environments, which, in turn, undermine the benefits of green areas to citizens, namely ecosystem services. 
The strong efforts to "build in green" is in many cases not adequately supported by a correct management that takes into account the plant response to stress related to the urban environment (e.g. air pollution, water shortage, nutrient deficiency, soil pollution, high temperatures) (Watson et al. 2014; Allen et al. 2017). Moreover, the aforementioned stressful conditions of an urban environment to which tree species are normally exposed, could become a more serious limiting factor due to the harness imposed by global climate change (Yang 2009; Churkina et al. 2015; Ordóñez and Duinker 2015; Cotrozzi et al. 2016, 2017).

Only little information is available about trees, climate change and urban environment interactions if compared to data from studies conducted on forests or natural ecosystems (Ordóñez and Duinker 2015; Pretzsch et al. 2017). A study conducted in Philadelphia found that the predicted global climate change effects will result in suboptimal growth conditions for ten commonly used tree species, while others will thrive (Yang 2009). If the climate change factors have adverse effects for some tree species, for others they may exert the opposite result. A worldwide analysis conducted by Pretzsch et al. (2017) selected 10 metropolises around the world over four climate zones and found interesting results about climate change factors and plant interactions. The authors concluded that heat island, in concomitance with climate change factors contributed 14 and $21 \%$ in accelerating the tree growth compared to the rural counterparts. This assumption strengthens the idea that not all tree species are negatively affected by urban environmental conditions, but tree species with different degrees of susceptibility would show different responses to urban stressors (Cotrozzi et al. 2018; Araminiene et al. 2019; Sicard et al. 2018; Landi et al. 2019). However, an acceleration of growth could also accelerate the process of senescence itself, thereby shortening the tree lifetime and requiring a more dynamic management of green areas by municipalities (Pretzsch et al. 2017).

Many efforts have yet to be done for the selection of trees suitable for a specific urban area, in view of the actual lack of a large selection of plants for urban environment (usually non selected native species are used) and the lack of contextualization of each species to the planting area (microclimate, soil conditions, water supply, light and other factors) (Sjöman et al. 2012). These factors have contributed to create low tree species diversity in urban areas by choosing the most popular tree species, which in turn may not result the best solution in terms of plant resilience to the urban environment (e.g. insect pests or fungal disease outbreak) (Sjöman et al. 2012; Vogt et al. 2017). The selection of trees that demonstrate a marked resistance to abiotic stresses should therefore be encouraged to respond to actual and future challenges of urban greening (Yang 2009; Sicard et al. 2018).

From an ornamental point of view, tree species may differ in shape, size, habitus (deciduous or evergreen) and also in crown color. All these macroscopic features translate into complex morpho-anatomical, allometric, physiological, and biochemical responses when plants sense a specific stress, and this can determine the success or the weakness of a specific tree species in a specific urban environment. Among others, recent studies have pointed the attention on trees species able to produce peculiar pigments in leaves, namely anthocyanins (ACNs), which confer them a well-appreciated red/purple coloration (Kyparissis et al. 2007; Hughes et al. 2007; Lo Piccolo et al. 2018). Acer platanoides L. var. schwedleri nigrum, A. pseudoplatanus L. var. atropurpureum, A. palmatum Thunb. var. atropurpureum, Fagus sylvatica L. var. atropunicea, Corylus maxima Mill. var. purpurea, Prunus cerasifera Ehrh. var. pissardii, Cercis canadensis L. var. forest pansy, Cotinus coggygria Scop. var. royal purple are the most widely used permanent red-leafed species for urban areas. These tree species have been selected by humans for their high ornamental value. However, besides their great aesthetic values, the constitutive presence of these colorful flavonoids on leaves, as shown in next sections, could also help these species to better accommodate some abiotic stressors, which is particularly advantageous for urban trees in the era of global climate change.

\section{Chemistry and ecological roles of ACNs}

ACNs are a conspicuous class of water-soluble pigments (ranging from pale pink, to red-purple and blue) which are responsible for the amazing color versatility of plant kingdom all around the world (Grotewold 2006). ACNs belong to the family of flavonoids, likely the most studies pathway of polyphenol metabolism in planta (Landi et al. 2015). ACNs are di- or tri-hydroxy B-ring-substituted flavonoids containing a flavylium cation which, owing to its conjugated double bonds, absorbs visible light with a peak in the $500-550 \mathrm{~nm}$ waveband (Fedenko et al. 2017). The wide range of anthocyanin-derived colors depends on the degree of hydroxylation and the number and/or type of substituted groups. To date, 17 anthocyanidins have been isolated, but most of these are found only in reproductive structures and only six aglycones (cyanidin, delphinidin, malvidin, pelargonidin, peonidin, and petunidin) have been identified in vegetative organs (Silva et al. 2016).

ACN pathway has been deeply studied in the last decades and this branch of phenylpropanoid metabolism has been extensively described, whereas their ecological roles is still a matter of argue. ACNs are synthetized in a wide range of plant tissues of different plant organs including leaves, flowers, fruits, roots, tubers and stems (Ellestad 2006; Winefield et al. 2009; Yoshida et al. 2009) and their possible ecological functions have puzzled scientists for well over a century. Mimicry, pollinator attraction, herbivory 
repellence, and protection from abiotic stresses are the major ecological roles proposed for this widespread class of pigments (Winefield et al. 2009). Though the hypothesis that ACNs may have a protective role in plants date back to 1879 (Pringsheim 1879), the way through which they accommodated environmental cues is still highly debated.

In the next section, the possible ameliorative role(s) exerted by ACNs in a modern urban environment (Fig. 1), naturally exposed to multiple abiotic stressors, is depicted with the attempt to highlight 'the privilege of being permanently red' in our cities in the age of global climate change.

\section{Benefits of foliar presence of ACNs for tree species in urban environment}

\section{Photoprotection}

\section{Sunscreen}

The term "photoprotection" is widely used with different meanings by scientists dealing with plant physiology, biochemistry, genetics and ecology. We will refer to "photoprotection" in its broader meaning, intended as "protection from light-triggered damages at all physiological/biochemical/ genetic level which induce depression of the photosynthetic process". In this context, ACNs can serve multiple roles in photoprotecting the leaves from abiotic-stress-promoted photosynthesis impairment, acting as sunscreens, reactive oxygen species (ROS)-scavengers and sugar buffering compounds.

The excess of light burden to photosynthetic apparatus can undermine the chloroplast functionality and yield, as testimony by a rapid decline in the quantum efficiency of photosystem II (PSII), and a reduction in carbon fixation (Murata et al. 2007; Gururani et al. 2015). Abiotic stressors, which can affect the whole plant status, including chloroplast, lead to an excess of excitation energy within photosynthetic apparatus (Murata et al. 2007) and trees in the urban environment are subjected to more abiotic stressors compared to trees grown in rural conditions (Sæbø et al. 2003). To avoid such an imbalance of light irradiance, plants have developed various morphological and physiological mechanisms, such as leaf or chloroplast movement, ROS scavenging systems, dissipation of absorbed light energy as heat, activation of cyclic electron flow and photorespiratory pathway (Takahashi and Badger 2011). Beside the aforementioned photoprotective mechanisms, ACNs, when localized in upper epidermis and mesophyll tissues, also constitute an effective sunblock, as reported for a different species, irrespectively to the fact that ACNs accumulate in the leaf mesophyll (Hughes and Smith 2007; Hughes et al. 2014) or in adaxial epidermis (Hughes et al. 2007; Landi et al. 2013a, b; Tattini et al. 2017).

The capacity of ACNs to absorb a proportion of the yellow/green and ultraviolet wavelengths (the latter especially when ACNs are acylated), may indeed significantly reduce the light-triggered damages to PSII, and in particular that related to D1 repair and the oxygen-evolving complex (Miyao et al. 1995; Antal et al. 2009; Takahashi and Badger 2011). Usually, under high irradiances, red-leafed individuals show lower level of other photoprotective pigments such as xanthophyll violaxanthin, antheraxanthin and zeaxanthin (VAZ), compared with green-leafed ones, which is consistent with the idea that ACNs might partially compensate for the photoprotective role of VAZ pool (Cavender-Bares et al. 1999; Verhoeven et al. 2005; Tattini et al. 2014; Logan et al. 2015; Lo Piccolo et al. 2018; Renner and Zohner 2019). In other cases, similar VAZ level were measured in both red and green leaves under optimal conditions, but when plants were subjected to high light, a stronger increment in VAZ de-epoxidation state in green than red leaves was observed, which is supportive for an alternative rather than compensatory role of ACNs (Hughes et al. 2012). Supportively to either an alternative or compensatory role of ACNs,

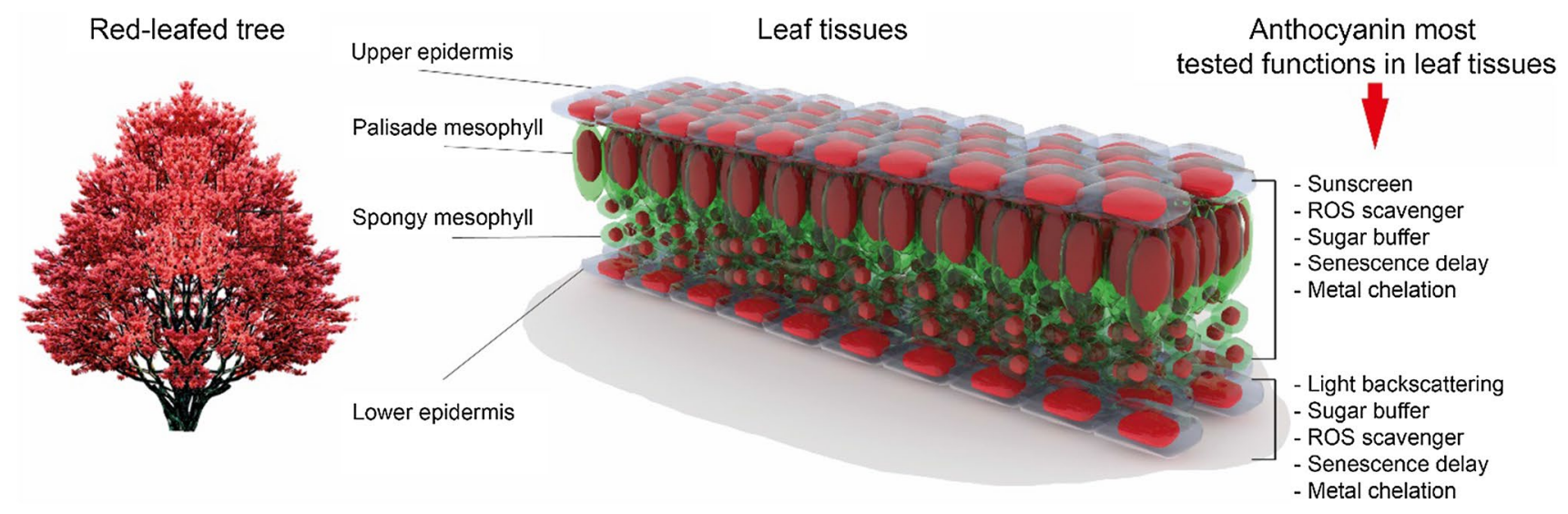

Fig. 1 Possible distribution of anthocyanins in leaf tissues of different plant species and their different role on the bases of their localization 
when an extra amount of red light (able to overpass the ACN layer) was supplied, ACN-equipped and $\mathrm{ACN}$-less leaves were similarly photoinhibited (Pietrini et al. 2002). When ACNs are localized in the lower epidermis, their possible sunscreen role appears inappropriate, leading to the hypothesis that ACNs localized in the lower epidermis may reflect adaxially-transmitted red light back to the mesophyll (Lee et al. 1979; Hughes et al. 2008). However, obtained results have failed to fully prove the functional significance of this trait, and further researches are needed (Hughes et al. 2008).

To date, only a few studies have investigated the performance of green- versus permanent red-leafed tree species in response to abiotic stresses which typically occur in cities, especially in the harsh Mediterranean area. However, these studies demonstrated the capacity of ACNs to protect the leaves from excessive light, thereby supporting 'the privilege of being permanently red', under condition of abiotic stress. For example, Lo Piccolo et al. (2018) and Vangelisti et al. (2020) observed that in vulnerable stages of leaves (young and senescent leaves), a red-leafed cv. of Prunus cerasifera, which is widely used in urban environment, was less susceptible to light excess than a green-leafed counterpart. In addition, Lo Piccolo et al. (2020a) observed that ACN presence ameliorates the performance of Prunus spp. in condition of limited water availability.

\section{ROS prevention and scavenging}

Abiotic stresses can consistently lead to an increase of ROS production over a physiological level in different cellular compartments, e.g., mitochondria and chloroplast, thereby promoting events of oxidative stress, oxidative burst and finally cell death (Foyer et al. 1994). Flavonoids, including ACNs, with poly-hydroxy B-ring substitutions, have been found to act as powerful ROS scavengers in in vitro experiments (Neill and Gould 2003; Juadjur et al. 2015). However, it is still under debate whether or not ACNs can serve as ROS scavenger in vivo, given that ACNs would only have the possibility to scavenge cytosolic and vacuolar ROS (whilst chloroplast and mitochondria with their electron transport chains are the primary sites for ROS production) before being shuttle to the vacuole (Hernández et al. 2009). In favor of their ROS scavenging role, the fact that ACNs can scavenge vacuolar $\mathrm{H}_{2} \mathrm{O}_{2}$, which, produced in other sites, can easily pass lipid bilayers and reach the vacuole which normally occupied more than $70 \%$ of a total cell volume (Mittler et al. 2004). $\mathrm{H}_{2} \mathrm{O}_{2}$ is indeed more stable than other radical ROS, and therefore vacuolar ANCs are likely to have a pivotal role in counteracting the symplastic movement of ROS (Mittler et al. 2004), which is supportive for the theory of Yamasaki's group (Yamasaki et al. 1996, 1997). Accordingly, lower levels of $\mathrm{H}_{2} \mathrm{O}_{2}$ were measured in red- than green-leafed Prunus during the last phase of leaf ontogenesis (Lo Piccolo et al. 2018). Besides the opinion about the scavenging role of ACNs, it is undeniable that the previous role as sunscreen compounds also results in reducing the amount of ROS that could be otherwise produced being that amount of light not intercepted by ACNs. Therefore, accepting the definition of an antioxidant as "a substance that, when present at low concentrations compared to those of an oxidizable substrate, significantly delays or prevents oxidation of that substrate" (Gutteridge and Halliwell 1990), it emerges clearly the weak borderline between the classic dichotomy in ACN roles: sunscreens or antioxidants (Landi et al. 2015).

\section{Sugar buffering}

The perturbation of plant metabolism by abiotic stressors can result in sugar accumulation, which, in turn, induces the sugar-promoted feedback inhibition of photosynthesis (Krapp and Stitt 1995; Paul and Foyer 2001; Holland et al. 2016). In view of their nature, it has been proposed that ACN accumulation may represent an alternative sugar sink, thereby preventing or delaying the sugar-promoted inhibition of photosynthesis of plants subjected to abiotic stresses (Landi et al. 2015; Lo Piccolo et al. 2018, 2020a, b; Gould et al. 2018). Indeed, ACN and sugar metabolism are strictly interconnected, and sugar-promoted enhancement of ACN levels has been clearly demonstrated in previous experiments (Solfanelli et al. 2006; Das et al. 2012; Lo Piccolo et al. 2018). In order to test this hypothesis in tree species, it was recently demonstrated that $\mathrm{ACN}$ biosynthesis represents a relevant $\mathrm{C}$-sink in conditions of imbalanced source-tosink relationship induced by the effect of stem bark girdling (Lo Piccolo et al. 2020b). It has also been demonstrated that under drought, one of the main constrains for trees in Mediterranean cities (Sjöman et al. 2018), red-leafed Prunus plants were less affected than ACN-less individuals. The increase of ACNs in the first phase of water stress resulted in lower accumulation of soluble sugars in leaves of red than green individuals and correlated with a lower decline of PSII efficiency (Lo Piccolo et al. 2020a). The ACN enhancement was therefore proposed by the authors as a mean to both reduce the incident light and reduce the sugar-promoted feedback regulation of photosynthesis.

\section{Senescence delay}

Connected to the sugar-buffering role previously described, the C-sink exerted by ACNs may also offer the possibility to stressed plant to avoid the phenomenon of early senescence promoted by foliar sugar accumulation (Sami et al. 2016). The strict interconnection between sugar, ACNs and senescence has been well described in red versus green autumn leaves by different authors (Feild 
et al. 2001; Hoch et al. 2003; Schaberg et al. 2003). In addition, a longer leaf life-span can increase the $\mathrm{N}$ resorption ability by the leaf, therefore reducing the loss of $\mathrm{N}$ due to earlier leaf fall (Feild et al. 2001; Hoch et al. 2003; Shi et al. 2017). Accordingly, Lo Piccolo et al. (2018) observed that accumulation of ACNs in older leaves of permanent red-leafed Prunus correlated with a delayed leaf senescence and a lower level of residual $\mathrm{N}$ into the leaves when compared to green-leafed individuals. This aspect can be particularly interesting in an urban environment, given that red species could maintain the leaves for longer than other green deciduous species at the end of autumn, thus further increasing the aesthetic value of ACN-rich tree species.

\section{Metal chelation capacity}

Metal accumulation and toxicity represent another hazardous risk for trees in an urban environment (Landi et al. 2020). Metal stress can induce ACN biosynthesis in a dose-dependent manner (Kumar et al. 1995; ChalkerScott 1999), but it remains yet to be elucidated in which way ACN may help the plant to cope with metal toxicity. Besides the photoprotective roles described above, ACNs possess a 3',4'-O-dihydroxyl group in the $\mathrm{B}$ ring of their backbone, which have the capacity to form metal-ACN complexes (Fedenko et al. 2017). The occurrence of metalACN complexes has been reported for different metals including $\mathrm{W}, \mathrm{Al}, \mathrm{Cd}, \mathrm{Cu}, \mathrm{Ga}, \mathrm{Fe}, \mathrm{Mo}, \mathrm{Mg}, \mathrm{Zn}$ (Fedenko et al. 2017 and reference therein). However, only Hale et al. $(2001,2002)$ tested this ameliorative role in vivo and, in addition, this capacity was proved for $\mathrm{W}$ and Mo, which are not among the most common metal pollutants in urban environments. The capacity of ACNs to bind metal ions can expedite their cytosolic sequestration, boosting their shuttle to the vacuole in coordination with glutathione, glutathione S-transferase and phytochelatins, which are common carriers for both ACNs and metals into the vacuoles (Landi et al. 2015). This would result in lowering their toxic impact to the cytosolic environment and preventing the metal diffusion to other organelles. In addition, in case of epidermally-located ACNs, the sequestration of metal ions into the leaf epidermis represent a mean to avoid metal accumulation in more important tissues (e.g. mesophyll cells).

In view of the above discussion, permanent red-leafed species seem to be better equipped to survive in metalenriched soils, even though future researches are needed to better understand whether the metal chelation ability of ACNs exerts a relevant role in metal tolerance of ACNequipped tree species.

\section{Possible argumentations against the use of red species in urban environment}

\section{Green means relax, red excitation}

Besides the previous undeniable biochemical/physiological aspects which suggest red-leafed tree species as more suitable to counteract the stressful conditions of cities, there are, maybe, some possible argumentations and concerns related to the use of these species from different point of views.

Chromotherapy highlights that green, which represents the most present color in nature, is a restful color that inspires harmony. Green is associated with spiritual balance, can diffuse anxiety and helps us to keep calm and controlled (Garala et al. 2009). Conversely, red is often described as warm, vibrant, and intense. It is often seen as an exciting and even aggressive color able to stimulate blood pressure and nerves (Azeemi and Raza 2005). Based on the aforementioned statements, it seems conceivable that the use of red species should be limited. However, it should be considered that red can also evoke feelings of love and comfort. Red is often used to grab attention, particularly in advertising and traffic signage. In addition, purple color, which is more common in tree species than pure red, may evoke relaxation, comfort and calmness too (Kaya and Epps 2004).

The use of "red" or better anthocyanin-rich species has to be therefore carefully pondered with the typical greenleafed trees in order not to create an unfavorable effect. For example, the foliage that is typical of North America's and Canada's autumn, appears as an amazing alternation of yellow/red/purple tonalities. Conversely, the only use of monotone red species for an urban park would not be appreciable given that the aesthetic value of tree species is one of the most important ecosystem services exerted by urban trees. Anthocyanin-rich trees should be therefore used to alert the observer, using red trees to mark particular paths, or, alternatively, they should be carefully balanced to green species to confer a strongly appreciated dichromatic contrast to the scenery.

\section{Constitutively red trees have been selected by humans; their use is against the natural plant evolution}

Perhaps is sad to be admitted, but nowadays the most widely diffused plant species have been selected by humans for their own purposes. Trees species are not an exception, and especially in the context of the urban greening, the aesthetic value, rapid growth, and in some cases the stress tolerance should be key requisites for their selection. So that, besides many efforts which have been done, especially in the last decade, agriculture as well as urban greening are far to be oriented in maintaining the plant biodiversity and following the evolutionary criteria. 
Constitutively permanent red-leafed tree species have been selected by humans for their high aesthetic value. However, if we consider the phylogenetic evolution of the ACN pathway, it emerges that ACNs are old pigments (the genes of the ACN pathway are thought to date back 450 million years to the first land plants) and this phenylpropanoid branch is present in all the angiosperm families (Campanella et al. 2014). Therefore, the human selection of red-leafed species have paralleled (and not contrasted) the evolution of ACNs and perhaps the leaf of the future will be transiently red for the majority of its ontogenetic cycle, especially in limiting environments.

\section{The biosynthesis of ACNs is an expensive pathway and red species have consequently a reduced growth rate}

As detailed above, ACN biosynthesis represents a relevant $\mathrm{C}$-sink and requires energy investment by the plant to keep this pathway active (Lo Piccolo et al. 2020b). Under optimal conditions, a comparison of the growth rate of anthocyaninrich versus ACN-less individuals would be in favor of the green ones (Landi et al. 2013a). However, when green and red plants were compared in stressful condition (the most common situation in an urban environment), usually red species are able to compensate for their apparent inability to compete with the growth rate of green-leafed individuals (Tattini et al. 2014), and in most cases they even exhibit superior performances (Landi et al. 2013a). Though the previous statements were derived from herbaceous species, due the lack of this kind of investigation in tree species, it is conceivable that the presence of foliar ACNs may also ameliorate tree performances under unfavorable environmental cues for all the reasons mentioned in the section "Benefits of foliar presence of ACNs for tree species in urban environment", which can be considered valid to both herbaceous of arborous species. Tree species seem therefore more successful in a stressful and limiting environment as the city, especially in Mediterranean areas.

\section{Conclusion and future perspectives}

$\mathrm{ACN}$-rich tree species represent a valid alternative, with an underestimated potential, to the most commonly used green species in urban environments. Future criteria for the selection of tree species should be improved in order to respond to the new challenges imposed by global climate change, which exacerbates the already harsh living conditions of our "leafed citizens". The aesthetic value attributable to the presence of foliar ACNs, associated to capacity of these pigments to be helpful in accommodating the common abiotic stress (typical of Mediterranean cities) should attract the attention of urban greening operators and promote their use, which is nowadays only marginally considered. New researches are still needed to deepen the pivotal aspects related to the ecophysiology of these permanently red-leafed species in relation to different urban environments, in order to wisely select the most suitable species in view of their peculiar features.

Acknowledgements The authors are thankful to Prof. Evgenios Agathokleous, who is the associate editor-in chief of Journal of Forestry Research, for the official invitation to publish the present review in Journal of Forestry Research.

Open Access This article is licensed under a Creative Commons Attribution 4.0 International License, which permits use, sharing, adaptation, distribution and reproduction in any medium or format, as long as you give appropriate credit to the original author(s) and the source, provide a link to the Creative Commons licence, and indicate if changes were made. The images or other third party material in this article are included in the article's Creative Commons licence, unless indicated otherwise in a credit line to the material. If material is not included in the article's Creative Commons licence and your intended use is not permitted by statutory regulation or exceeds the permitted use, you will need to obtain permission directly from the copyright holder. To view a copy of this licence, visit http://creativecommons.org/licenses/by/4.0/.

\section{References}

Allen KS, Harper RW, Bayer A, Brazee NJ (2017) A review of nursery production systems and their influence on urban tree survival. Urban For Urban Green 21:183-191. https://doi. org/10.1016/j.ufug.2016.12.002

Antal TK, Lo W, Armstrong WH, Tyystjärvi E (2009) Illumination with ultraviolet or visible light induces chemical changes in the water-soluble manganese complex, [Mn4O6 (bpea)4] Br4. Photochem Photobiol 85:663-668. https://doi.org/10.111 1/j.1751-1097.2008.00502.x

Araminiene V, Sicard P, Anav A et al (2019) Trends and inter-relationships of ground-level ozone metrics and forest health in Lithuania. Sci Tot Environ 658:1265-1277

Azeemi STY, Raza M (2005) A Critical analysis of chromotherapy and its ccientific evolution. Evid Based Complement Alternat Med 2:481-488. https://doi.org/10.1093/ecam/neh137

Berland A, Shiflett SA, Shuster WD et al (2017) The role of trees in urban stormwater management. Landsc Urban Plan 162:167177. https://doi.org/10.1016/j.landurbplan.2017.02.017

Campanella JJ, Smalley JV, Dempsey ME (2014) A phylogenetic examination of the primary anthocyanin production pathway of the Plantae. Bot Stud 55:10. https://doi. org/10.1186/1999-3110-55-10

Cavender-Bares J, Apostol S, Moya I et al (1999) Chilling-Induced photoinhibition in two oak species: Are evergreen leaves inherently better protected than deciduous leaves? Photosynthetica 36:587-596. https://doi.org/10.1023/A:1007000406399

Chalker-Scott L (1999) Environmental significance of anthocyanins in plant stress responses. Photochem Photobiol 70:1-9. https://doi. org/10.1111/j.1751-1097.1999.tb01944.x 
Churkina G, Grote R, Butler TM, Lawrence M (2015) Natural selection? Picking the right trees for urban greening. Environ Sci Policy 47:12-17. https://doi.org/10.1016/j.envsci.2014.10.014

Cotrozzi L, Remorini D, Pellegrini E et al (2016) Plasticity of physiological and biochemical traits can assist oak species under drought and ozone in Mediterranean environment. Physiol Plantarum 157:69-84

Cotrozzi L, Remorini D, Pellegrini E et al (2017) Cross-talk between physiological and metabolic adjustments adopted by Quercus cerris to mitigate the effects of severe drought and realistic future ozone concentrations. Forests 8:148

Cotrozzi L, Remorini D, Pellegrini E et al (2018) Living in a Mediterranean city in 2050: broadleaf or evergreen 'citizens'? Environ Sci Pollut Res 25:8161-8173

Das PK, Shin DH, Choi S-B, Park Y-I (2012) Sugar-hormone cross-talk in anthocyanin biosynthesis. Mol Cells 34:501-507. https://doi. org/10.1007/s10059-012-0151-x

Ellestad GA (2006) Structure and chiroptical properties of supramolecular flower pigments. Chirality 18:134-144. https://doi. org/10.1002/chir.20228

Fedenko VS, Shemet SA, Landi M (2017) UV-vis spectroscopy and colorimetric models for detecting anthocyanin-metal complexes in plants: an overview of in vitro and in vivo techniques. J Plant Physiol 212:13-28. https://doi.org/10.1016/j.jplph.2017.02.001

Feild TS, Lee DW, Holbrook NM (2001) Why leaves turn red in autumn. The role of anthocyanins in senescing leaves of red-osier dogwood. Plant Physiol 127:566-574

Foyer CH, Lelandais M, Kunert KJ (1994) Photooxidative stress in plants. Physiol Plant 92:696-717. https://doi. org/10.1111/j.1399-3054.1994.tb03042.x

Garala K, Basu B, Bhalodia R et al (2009) Alternative to drug delivery system: Chromotherapy. Drug Invent Today 1:130-134

Gould KS, Jay-Allemand C, Logan BA et al (2018) When are foliar anthocyanins useful to plants? Re-evaluation of the photoprotection hypothesis using Arabidopsis thaliana mutants that differ in anthocyanin accumulation. Environ Exp Bot 154:11-22. https:// doi.org/10.1016/j.envexpbot.2018.02.006

Grotewold E (2006) The genetics and biochemistry of floral pigments. Annu Rev Plant Biol 57:761-780. https://doi.org/10.1146/annur ev.arplant.57.032905.105248

Gururani MA, Venkatesh J, Tran LSP (2015) Regulation of photosynthesis during abiotic stress-induced photoinhibition. Mol Plant 8:1304-1320. https://doi.org/10.1016/j.molp.2015.05.005

Gutteridge JMC, Halliwell B (1990) The measurement and mechanism of lipid peroxidation in biological systems. Trends Biochem Sci 15:129-135. https://doi.org/10.1016/0968-0004(90)90206-Q

Hale KL, McGrath SP, Lombi E et al (2001) Molybdenum sequestration in Brassica species. A role for anthocyanins? Plant Physiol 126:1391-1402. https://doi.org/10.1104/pp.126.4.1391

Hale KL, Tufan HA, Pickering IJ et al (2002) Anthocyanins facilitate tungsten accumulation in Brassica. Physiol Plant 116:351-358. https://doi.org/10.1034/j.1399-3054.2002.1160310.x

Hernández I, Alegre L, Van Breusegem F, Munné-Bosch S (2009) How relevant are flavonoids as antioxidants in plants? Trends Plant Sci 14:125-132. https://doi.org/10.1016/j.tplants.2008.12.003

Hoch WA, Singsaas EL, McCown BH (2003) Resorption protection. anthocyanins facilitate nutrient recovery in autumn by shielding leaves from potentially damaging light levels. Plant Physiol 133:1296-1305. https://doi.org/10.1104/pp.103.027631

Holland V, Fragner L, Jungcurt T et al (2016) Girdling interruption between source and sink in Quercus pubescens does not trigger leaf senescence. Photosynthetica 54:589-597. https://doi. org/10.1007/s11099-016-0646-3

Hughes NM, Burkey KO, Cavender-Bares J, Smith WK (2012) Xanthophyll cycle pigment and antioxidant profiles of winter-red (anthocyanic) and winter-green (acyanic) angiosperm evergreen species. J Exp Bot 63:1895-1905. https://doi.org/10.1093/jxb/ err362

Hughes NM, Carpenter KL, Keidel TS et al (2014) Photosynthetic costs and benefits of abaxial versus adaxial anthocyanins in Colocasia esculenta 'Mojito'. Planta 240:971-981. https://doi. org/10.1007/s00425-014-2090-6

Hughes NM, Morley CB, Smith WK (2007) Coordination of anthocyanin decline and photosynthetic maturation in juvenile leaves of three deciduous tree species. New Phytol 175:675-685. https ://doi.org/10.1111/j.1469-8137.2007.02133.x

Hughes NM, Smith WK (2007) Attenuation of incident light in Galax urceolata (Diapensiaceae): concerted influence of adaxial and abaxial anthocyanic layers on photoprotection. Am J Bot 94:784 790. https://doi.org/10.3732/ajb.94.5.784

Hughes NM, Vogelmann TC, Smith WK (2008) Optical effects of abaxial anthocyanin on absorption of red wavelengths by understorey species: revisiting the back-scatter hypothesis. J Exp Bot 59:3435-3442. https://doi.org/10.1093/jxb/ern193

Juadjur A, Mohn C, Schantz M et al (2015) Fractionation of an anthocyanin-rich bilberry extract and in vitro antioxidative activity testing. Food Chem 167:418-424. https://doi.org/10.1016/j.foodc hem.2014.07.004

Kaya N, Epps H (2004) Relationship between color and emotion: a study of college students. Coll Stud 38:396

Krapp A, Stitt M (1995) An evaluation of direct and indirect mechanisms for the "sink-regulation" of photosynthesis in spinach: changes in gas exchange, carbohydrates, metabolites, enzyme activities and steady-state transcript levels after cold-girdling source leaves. Planta. https://doi.org/10.1007/BF00202587

Kumar PBAN, Dushenkov V, Motto H, Raskin I (1995) Phytoextraction: the use of plants to remove heavy metals from soils. Environ Sci Technol 29:1232-1238. https://doi.org/10.1021/es00005a014

Kyparissis A, Grammatikopoulos G, Manetas Y (2007) Leaf morphological and physiological adjustments to the spectrally selective shade imposed by anthocyanins in Prunus cerasifera. Tree Physiol 27:849-857. https://doi.org/10.1093/treephys/27.6.849

Landi M, Cotrozzi L, Pellegrini E et al (2019) When "thirsty" means "less able to activate the signalling wave trigged by a pulse of ozone": a case of study in two Mediterranean deciduous oak species with different drought sensitivity. Sci Tot Environ 657:379-390

Landi M, Shemet S, Fedenko V (eds) (2020) Metal toxicity in higher plants. Nova Science Publishers Inc., New York

Landi M, Guidi L, Pardossi A et al (2014) Photoprotection by foliar anthocyanins mitigates effects of boron toxicity in sweet basil (Ocimum basilicum). Planta 240:941-953. https://doi. org/10.1007/s00425-014-2087-1

Landi M, Pardossi A, Remorini D, Guidi L (2013a) Antioxidant and photosynthetic response of a purple-leaved and a green-leaved cultivar of sweet basil (Ocimum basilicum) to boron excess. Environ Exp Bot 85:64-75. https://doi.org/10.1016/j.envex pbot.2012.08.008

Landi M, Remorini D, Pardossi A et al (2013b) Sweet basil (Ocimum basilicum) with green or purple leaves: which differences occur in photosynthesis under boron toxicity? J Plant Nutr Soil Sci 176:942-951

Landi M, Tattini M, Gould KS (2015) Multiple functional roles of anthocyanins in plant-environment interactions. Environ Exp Bot 119:4-17. https://doi.org/10.1016/j.envexpbot.2015.05.012

Lee DW, Lowry JB, Stone BC (1979) Abaxial anthocyanin layer in leaves of tropical rain forest plants: Enhancer of light capture in deep shade. Biotropica 11:70-77. https://doi.org/10.2307/2388175 
Lo Piccolo E, Landi M, Giordani T et al (2020a) Can anthocyanin presence help Prunus saplings to alleviate water stress effects in an urban environment? Photosynthetica (in press)

Lo Piccolo E, Landi M, Massai R et al (2020b) Girled-induced anthocyanin accumulation in red-leafed Prunus cerasifera: Effect on photosynthesis, photoprotection and sugar metabolism. Plant Sci 294:110456. https://doi.org/10.1016/j.plantsci.2020.110456

Lo Piccolo E, Landi M, Pellegrini E et al (2018) Multiple consequences induced by epidermally-located anthocyanins in young, mature and senescent leaves of Prunus. Front Plant Sci 9:917. https://doi. org/10.3389/fpls.2018.00917

Logan BA, Stafstrom WC, Walsh MJL et al (2015) Examining the photoprotection hypothesis for adaxial foliar anthocyanin accumulation by revisiting comparisons of green- and red-leafed varieties of coleus (Solenostemon scutellarioides). Photosynth Res 124:267-274. https://doi.org/10.1007/s11120-015-0130-0

McDonnell MJ, MacGregor-Fors I (2016) The ecological future of cities. Science 352:936-938. https://doi.org/10.1126/science.aaf36 30

Mittler R, Vanderauwera S, Gollery M, Van Breusegem F (2004) Reactive oxygen gene network of plants. Trends Plant Sci 9:490-498. https://doi.org/10.1016/j.tplants.2004.08.009

Miyao M, Ikeuchi M, Yamamoto N, Ono T (1995) Specific degradation of the D1 protein of photosystem II by treatment with hydrogen peroxide in darkness: Implications for the mechanism of degradation of the D1 protein under illumination. Biochemistry 34:10019-10026. https://doi.org/10.1021/bi00031a025

Murata N, Takahashi S, Nishiyama Y, Allakhverdiev SI (2007) Photoinhibition of photosystem II under environmental stress. Biochim Biophys Acta BBA - Bioenerg 1767:414-421. https://doi. org/10.1016/j.bbabio.2006.11.019

Neill SO, Gould KS (2003) Anthocyanins in leaves: light attenuators or antioxidants? Funct Plant Biol 30:865. https://doi.org/10.1071/ FP03118

Ordóñez C, Duinker PN (2015) Climate change vulnerability assessment of the urban forest in three Canadian cities. Clim Change 131:531-543. https://doi.org/10.1007/s10584-015-1394-2

Paul MJ, Foyer CH (2001) Sink regulation of photosynthesis. J Exp Bot 52:1383-1400. https://doi.org/10.1093/jexbot/52.360.1383

Pietrini F, Iannelli MA, Massacci A (2002) Anthocyanin accumulation in the illuminated surface of maize leaves enhances protection from photo-inhibitory risks at low temperature, without further limitation to photosynthesis. Plant, Cell Environ 25:1251-1259. https://doi.org/10.1046/j.1365-3040.2002.00917.x

Pretzsch H, Biber P, Uhl E et al (2017) Climate change accelerates growth of urban trees in metropolises worldwide. Sci Rep 7:15403. https://doi.org/10.1038/s41598-017-14831-w

Pringsheim N (1879) Ueber lichtwirkung und chlorophyll function in der pflanze. Ahrbücher Für Wiss Bot

Renner SS, Zohner CM (2019) The occurrence of red and yellow autumn leaves explained by regional differences in insolation and temperature. New Phytol 224:1464-1471

Sæbø A, Benedikz T, Randrup TB (2003) Selection of trees for urban forestry in the Nordic countries. Urban For Urban Green 2:101114. https://doi.org/10.1078/1618-8667-00027

Sami F, Yusuf M, Faizan M et al (2016) Role of sugars under abiotic stress. Plant Physiol Biochem 109:54-61. https://doi. org/10.1016/j.plaphy.2016.09.005

Schaberg PG, van den Berg AK, Murakami PF et al (2003) Factors influencing red expression in autumn foliage of sugar maple trees. Tree Physiol 23:325-333. https://doi.org/10.1093/treep hys/23.5.325
Shi C, Watanabe T, Koike T (2017) Leaf stoichiometry of deciduous tree species in different soils exposed to free-air $\mathrm{O}_{3}$ enrichment over two growing seasons. Environ Exp Bot 138:148-163

Sicard P, Agathokleous E, Araminiene A et al (2018) Should we see urban trees as effective solutions to reduce increasing ozone levels in cities? Environ Pollut 243:163-176

Silva VO, Freitas AA, Maçanita AL, Quina FH (2016) Chemistry and photochemistry of natural plant pigments: The anthocyanins. J Phys Org Chem 29:594-599. https://doi.org/10.1002/poc.3534

Sjöman H, Hirons AD, Bassuk NL (2018) Improving confidence in tree species selection for challenging urban sites: a role for leaf turgor loss. Urban Ecosyst 21:1171-1188. https://doi.org/10.1007/ s11252-018-0791-5

Sjöman H (2012) Trees for tough urban sites-learning from nature. Doctoral thesis. Dept. of Landscape Management, Design and Construction, Swedish University of Agricultural Sciences, Alnarp

Solfanelli C, Poggi A, Loreti E et al (2006) Sucrose-specific induction of the anthocyanin biosynthetic pathway in Arabidopsis. Plant Physiol 140:637-646. https://doi.org/10.1104/pp.105.072579

Song XP, Tan PY, Edwards P, Richards D (2018) The economic benefits and costs of trees in urban forest stewardship: a systematic review. Urban For Urban Green 29:162-170. https://doi. org/10.1016/j.ufug.2017.11.017

Takahashi S, Badger MR (2011) Photoprotection in plants: a new light on photosystem II damage. Trends Plant Sci 16:53-60. https://doi. org/10.1016/j.tplants.2010.10.001

Tattini M, Landi M, Brunetti C et al (2014) Epidermal coumaroyl anthocyanins protect sweet basil against excess light stress: multiple consequences of light attenuation. Physiol Plant 152:585-598. https://doi.org/10.1111/ppl.12201

Tattini M, Sebastiani F, Brunetti C et al (2017) Dissecting molecular and physiological response mechanisms to high solar radiation in cyanic and acyanic leaves: a case study on red and green basil. J Exp Bot 68:2425-2437

Tyrväinen L, Pauleit S, Seeland K, de Vries S (2005) Benefits and uses of urban forests and trees. In: Konijnendijk C, Nilsson K, Randrup T, Schipperijn J (eds) urban forests and trees. Springer, Berlin, pp 81-114

Vangelisti A, Guidi L, Cavallini A et al (2020) Red versus green leaves: transcriptomic comparison of foliar senescence between two Prunus cerasifera genotypes. Sci Rep 10:1959. https://doi. org/10.1038/s41598-020-58878-8

Verhoeven AS, Swanberg A, Thao M, Whiteman J (2005) Seasonal changes in leaf antioxidant systems and xanthophyll cycle characteristics in Taxus $\mathrm{x}$ media growing in sun and shade environments. Physiol Plant 123:428-434. https://doi.org/10.111 1/j.1399-3054.2005.00471.x

Vogt J, Gillner S, Hofmann M et al (2017) Citree: A database supporting tree selection for urban areas in temperate climate. Landsc Urban Plan 157:14-25. https://doi.org/10.1016/j.landurbpla n.2016.06.005

Watson GW, Hewitt AM, Custic M, Lo M (2014) The management of tree root systems in urban and suburban settings: a review of soil influence on root growth. Arboric Urban For 40:193-217

Winefield C, Davies K, Gould K (eds) (2009) Anthocyanins. Springer, New York

Xing Y, Brimblecombe P (2020) Trees and parks as "the lungs of cities". Urban For Urban Green 48:126552. https://doi.org/10.1016/j. ufug.2019.126552

Yamasaki H, Sakihama Y, Ikehara N (1997) Flavonoid-peroxidase reaction as a detoxification mechanism of plant cells against H2O2. Plant Physiol 115:1405-1412. https://doi.org/10.1104/ pp.115.4.1405 
Yamasaki H, Uefuji H, Sakihama Y (1996) Bleaching of the red anthocyanin induced by superoxide radical. Arch Biochem Biophys 332:183-186. https://doi.org/10.1006/abbi.1996.0331

Yang J (2009) Assessing the impact of climate change on urban tree species selection: a case study in Philadelphia. J For 107:364-372. https://doi.org/10.1093/jof/107.7.364

Yoshida K, Mori M, Kondo T (2009) Blue flower color development by anthocyanins: from chemical structure to cell physiology. Nat Prod Rep 26:884. https://doi.org/10.1039/b800165k
Zuo J, Zhao Z-Y (2014) Green building research-current status and future agenda: a review. Renew Sustain Energy Rev 30:271-281. https://doi.org/10.1016/j.rser.2013.10.021

Publisher's Note Springer Nature remains neutral with regard to jurisdictional claims in published maps and institutional affiliations. 